\title{
A New Look at Chinese Network Catchphrases
}

\author{
Hongyan Hua \\ College of International Studies, Southwest University, China
}

\begin{abstract}
This paper explores how contextual factors govern the meaning making of Chinese network catchphrases. Kovecses' context theory concerning metaphor studies is used as the theoretical framework to make a research into the metaphorical meaning making in Chinese network catchphrases. According to Kovecses, context in metaphor can be classified into four kinds, namely, situational context, discourse context, bodily context and conceptual-cognitive context, among which situational context can be further divided into physical environment situation context, social situation context and cultural situation context. By careful examination of Chinese network catchphrases from the contextual perspective, it is concluded that the meaning making of Chinese network catchphrases is not just a mapping process between two domains, a view that the traditional metaphor theory has always been adhering to, but a context-driven and emerging process in which various contextual factors have played their roles. And this conclusion seems to be more in line with the new discovery of the nature of human cognition, that is, embodied cognition.
\end{abstract}

Index Terms-Chinese network catchphrases, context, meaning making, context-driven, emerging

\section{INTRODUCTION}

Language is the reflection of an era and mirror of society. With the rapid development of information technology, especially mediums of transmission, a lot of Chinese network catchphrases have come into being and become popular in various walks of life. Apart from their own features of being economical in wording and conveying creative and metaphorical meanings in vivid manners, the reason why these Chinese network catchphrases win their popularity is that there are creative metaphors entailed in them.

Metaphor, regarded as "a matter of thought and action and only derivatively a matter of language" (Lakoff \& Johnson,1980,p.153), has always been a hot topic in language studies. This article will focus on a particular kind of metaphorical expression — Chinese network catchphrases, trying to give an account of how and why these metaphorical expressions are possible from the perspective of context, and mainly selects Chinese network catchphrases during these ten years as data to support our research. It takes Kovecses' context theory concerning metaphor studies as its theoretical framework, exploring how context is involved in the meaning making of Chinese network catchphrases, and the exploration is mainly confined to two important questions:

First, what are the contexts that underline the meaning making of Chinese network catchphrases? Second, how do these contexts govern the meaning making of Chinese network catchphrases?

In the following parts, these two questions will be addressed in turn. The main viewpoint in response to the first question will be that there are four kinds of contexts that underline the production and interpretation of Chinese network catchphrases, namely, situational context, discourse context, bodily context and conceptual-cognitive context. Turing to the second question, it is argued that in this article the role of the body in the meaning making of Chinese network catchphrases should be reinterpreted, that is to say, the body is just one of the several contexts from which Chinese network catchphrases can emerge and the meaning making of Chinese network catchphrases is accordingly an emergent process of several contexts.

\section{STUdies ON Chinese NETwork CATCHPHRASES}

As a novel language phenomenon, Chinese network catchphrases have drawn the attention of scholars from different fields, say, linguistic field, the field of communication, psychology, sociology and so on. Since this article is about language research, literature review of it should be conducted mainly from linguistic perspectives, which roughly includes the pragmatic perspective, semantic perspective and cognitive perspective.

Let's begin with the literature review in pragmatics. Much of the pragmatic studies of Chinese network catchphrases are carried out under the guidance of economy principle, politeness principle, memetics and other pragmatic theories, explaining how Chinese network catchphrases spread as well as their social and cultural function. For example, $\mathrm{He}$ Ziran (2014) gives a detailed interpretation of Chinese network catchphrases from the perspective of memetics and explains why they are popular. Some researchers approach their studies from pragmatic aspects, namely contextual features, linguistic style and stylistic features, which is a leap forward in the pragmatic study of network catchphrases (LinYun, 2012).Still there are some others who take theory of adaptation as their theoretical foundation. Besides the pragmatic approach, a lot of researchers also show great interests in the semantic aspects of Chinese network catchphrases, placing their emphases on the semantic variation of them. Although these semantic studies do elaborate a lot on the quick semantic deviation of Chinese network catchphrases, they fail to mention the concerned meaning 
making processes.

Nowadays, with cognitive linguistics becoming popular, more and more researchers begin to give cognitive accounts of Chinese network catchphrases, using theories of conceptual metaphor, conceptual blending, construction grammar etc to explain the mental activities going on in the mind. However, among these researchers, most of them are inclined to take a conceptual metaphor approach towards their studies. Conceptual metaphors are made up of "sets of systematic correspondences, or mappings, between two domains of experience" (Kovecses, 2015, p.ix), under the guidance of which, the meaning of one certain metaphorical expression realizing an underlying conceptual metaphor is based on such correspondences. Or, in other words, the inner activities of metaphorical meaning making are "described in terms of the mappings between different kinds of abstract, schematic, disembodied knowledge" (GIBBS, 2006b, p.434). All this has brought about the situation that there appear a lot of followers of conceptual metaphor theory who are confined to metaphors prestored in human's conceptual system and ignore the contextual factors when carrying out their research. In addition to this, despite its overwhelming influence, however, in recent years, with the new paradigm of embodied cognition or grounding cognition being widespread, conceptual metaphor theory has been criticized by a large number of scholars, and the essence of these criticisms comes from its failing to pay enough attention to the contextual factors concerning metaphorical expressions' actual occurrence (Kovecses, 2010).

From what has been reviewed above, it can be seen that researchers have laid much of their emphasis on the generation, transmission and formation of Chinese network catchphrases as well as the conceptual metaphors which underline them. Nevertheless, they have, to a certain extend, ignored the significance of context in their studies. Even those researchers who are engaged in studying the meaning making of Chinese network catchphrases still follow a context- absence style, unable to integrate context into the model of metaphorical meaning making. Starting from this, it seems much more obliged for us to include context into the study of Chinese network catchphrases. So, in this article, a new theory of contexts in metaphor, which is put forward by Kovecses, is introduced and made as the theoretical foundation of this research. Kovecses' context theory not only gives a clear explanation of various contextual factors that are involved in shaping human's conceptual system but also discusses in a detailed manner how these contextual factors work in the conceptualization of metaphorical utterances.

\section{CONTEXT Classification THEORY}

In this part, by introducing Kovecses' classification of context in metaphor, a reply to the first question raised in introduction will be given, and then in part 4 through an analysis of Chinese network catchphrases from the perspective of context, the second question will be answered. Before discussion of context classification, it is necessary to have a general idea of what context is.

Context has for a long time been a concern in the field of semantics, pragmatics, philosophy and other disciplines and finally become one of the most popular topics of research in the $21^{\text {st }}$ century. Its popularity in various disciplines bears a lot to the linguistic turn which happened in the $20^{\text {th }}$ century. Due to the linguistic turn, the emphasis in language study has been shifted from language structure to language function, which in turn brings about the emergence of various disciplines that value the importance of linguistic function, such as pragmatics, sociolinguistics, functional linguistics and applied linguistics. Subsequently there comes the situation that context has gained unprecedented attention for its critical role in analyzing linguistic function.

Despite this, context studies have not been so satisfying. As for context itself, up to now, there has not been a unified and fixed definition of it since scholars with different backgrounds hold different views towards it. For example, Chinese scholars He Ziran \& Ran Yongping (2006) regard context as one of the three key elements in interaction except for language user and the language used; Malinowski (1930) defines context as the culture, the social life and the custom in which a language is used; Firth(1951) holds the opinion that context consists of series of situational context and that each smaller one is embedded into a larger one to the extent that all the situational contexts have their significant role in the whole cultural context; Halliday's contribution to context study is his putting forward of the notion "register"(Halliday,1975); Lyons (1977) emphases the embodiment of context by stating that utterances' fitness for one certain situation relies on the knowledge that speakers possess; van Dijk $(2008,2009)$ thinks context is not merely about the objective social situations themselves but a mixture of objective social situations and participants' subjective representations of the social situations and that context is a special and dynamic metal model.

In light of what have been discussed above, it seems clear that despite difficulties in defining context, there are indeed some improvements in this defining process, and we begin to think about a question that has close kinship to context's definition, that is, classifications of context.

As for classifications of context, Wang Jianhua (2002) gives a summary of what have been achieved by previous scholars, saying that context classification can be different according to different criteria. For example, if approached from the criterion of function, context can be classified into objective context, subjective context and temporary subjective context; there also exist dynamic context and static context if the classification is conducted according to the criterion of stability; Besides, he also gives his own classification of in-language context, by-language context and ex-language context, among which in-language context can be further divided into inter-sentential context and textual context, by-language context into physical context and accompanying context and ex-language context into social-cultural context and cognitive context. Leech (1983) states that there are some other context classifications, 
according to which context can be classified into linguistic context, non-linguistic context, direct context and indirect context.

From the above, we can see that although a lot of work have been done, there still exists much more space for context classification to be further refined. Here this article will introduce the latest context classification put forward by Kovecses (2015) who classifies context in a more refined manner when he is conducting metaphor studies. According to his view, there are two major kinds of contexts: local context and global context. The former refers to the specific knowledge communicators have about some aspects of one immediate communicative situation, while the latter is about communicators' general knowledge of the non-immediate situation that characterizes a community. Kovecses also adds that there is not a sharp dividing line between these two contexts but a gradient from which the local context will have the tendency to turn into the global one. However, this rough classification of context into the local and global one is not the end in his discussion. Again Kovecses puts forward a relatively precise classification by dividing these two contexts into four refined ones, that is, situational context, discourse context, bodily context and conceptual-cognitive context.

Given that Chinese network catchphrase is one kind of metaphorical expression realized in network communication, here by introducing the four kinds of contexts in metaphor a reply to the first question is given: Kovecses' classification of context in metaphor is applicable to the context concerned in the study of Chinese network catchphrase, that is to say, there are also four kinds of contexts governing the meaning making of Chinese network catchphrases.

\section{COnTEXtual Analysis OF Chinese Network CATCHPHRASES}

In this part, context classification theory proposed by Kovecses will be applied in the contextual analysis of Chinese network catchphrases. That is to say, a detailed explanation of the four kinds of contexts as well as a discussion of how these contextual factors influence Chinese network catchphrases' conceptualization process will be conducted.

\section{A. Analysis from the Situational Context}

The key element of situational context is "situation", which can be further divided into physical environment situation, social situation and cultural situation. In order to know how these situations shape metaphorical meaning, it is necessary to have a comparatively clear understanding of them. We will begin with the physical environment context.

Physical environment is a term of broad sense, ranging from particular flora, fauna, landscape, temperature, weather, to dwellings, other people and so forth that people living in a certain region habitually interact with. Different people live in different physical environment and usually they are not so conscious to these differences, which in turn bring about the fact that metaphorical utterances that people speaking different languages and varieties of languages use will also be various. For example, American English is a language developed in a different physical environment, that is, North America, and the metaphors that American English speakers use are characteristically different from those which are used by people from other English speaking countries. (Kovecses, 2005) Apart from the influence of the large-scale physical environment on the choice of metaphors, the small-scale, local physical environment also has its influence on the shaping of particular metaphors in discourses or utterances. Put it simply, it is the influence of the physical environment upon its speakers that affects the metaphorical meaning making and subsequently the choice of metaphors. Here an example from Kovecses'book will be cited to illustrate this . The physical environment in which the metaphorical utterance happened is like this: there was the G8 summit meeting held in Scotland in 2005, and meanwhile a major rock concert called Live 8 was also held there. As for the assessments of the summit, some participants thought highly of it, while others didn't; and those who didn't of course gave such a negative comment as the following one:

(1) Dr Kumi Naidoo, from the anti-poverty lobby group G-Cap, said after the“roar"produced by Live 8,the G8 had uttered "a whisper". (Semino, 2008)

Here in this example there was a metaphorical expression "a whisper" which means "lack of resolve and effectiveness". Obviously the production of this metaphorical expression stems from the local physical environment — the holding of Live 8 rock concert. It is known to us that one important physical feature of a concert is its loudness, which is in contrast to the silent situation of the summit. So, for the participant, the meaning making of the metaphorical expression "whisper" arises from the physical context in which there is a very loud concert and a comparatively quiet summit meeting.

Social situation involves a lot of elements, say, social relationship, gender roles etc, and they can affect the shaping of metaphorical meaning making as well. One typical example of situational context is the distinctions between men and women, which in turn influence men's and women's choices of metaphors .According to Kolodny (1975, 1984), due to gender roles, American men and women exploit extremely different images when they conceptualize the world. For example, men tend to think of the frontier as a virgin land to be taken, whereas women always conceptualize it by means of the image of a garden.

The last branch in situational context is cultural situation context. In cultural situation context, there are unique and salient concepts and values that characterize particular cultures as well as the governing principles of a given culture. For people of a certain culture, these concepts and values have permeated into some domains of their experience, and accordingly have played a crucial role in their conceptualization of the world. Boers \& Demecheleer (1997, 2001) point out that due to their salience in a certain culture concepts of hat and ship contribute more in the production of 
metaphorical idioms in English than in French. And this is also true in Chinese metaphorical meaning making, for example, in Chinese, due to the Yin and Yang culture there is an "ANGER IS GAS" conceptual metaphor and its corresponding linguistic metaphors.

Then, how do situational context influences the meaning making of Chinese network catchphrases? Consider the following examples:
(2) 我的 评论
Wo de pinglun
“上墙”
shangqiang
了! le !
my opinion on the wall of a building
"My opinion became public on the screen of microblog."
(3) 村 务 “上墙”.
Cun wu
village affairs on the wall of a building.
"village affairs became public on the screen of microblog."
(4) 麦莎比预计 晚了个小时。
Maisha bi yuji wan le ji ge xiaoshi
Maisha compare expection late several hour
"Compared to expection , Maisha was late for several hours."
(5) 麦莎 轻轻 地 掠过 这座 城市, 却是 那样的 温柔。
Maisha qingqing di lveguo zhe zuo chengshi, que shi nayang de wenrou.
Maisha quietly sway this city, still so gentle.

"Maisha swayed this city quietly ,still so gentle."

The new metaphorical expression“"shangqiang (上墙)" has the figurative meaning that new or interesting things sent out by netizens are made public on the screen of microblog. And in this new expression, there is an underlying metaphor "NETWORK IS A BUILDING", which governs the linguistic realization"shangqiang (上墙)". But how does that underlying metaphor come about? This has something to do with the development of network in modern times, that is, the social situation, which subsequently brings about the fact that network, for us, is as important and essential as buildings, and therefore we are justified to use the concept "BUILDING" to understand the concept "NETWORK". Just as buildings have walls on which we can poster some paper expressing our thoughts, we can also poster our opinions upon the network. It is obvious that the situational context of network's development triggers the underlying metaphor "NETWORK IS A BUILDING" and its corresponding linguistics metaphors.

As for"Maisha(麦莎)"'in examples (4) and (5), it can be easily got that there is an underlying metaphor "NATURAL DISASTER IS A PERSON", the meaning construction of which is due to the physical environment of typhoon's coming in this example and people's awareness of the similarity between the slow coming of typhoon and the slow pace of a high-heeled women during her walk.

\section{B. Analysis from the Discourse Context}

Discourse is made up of elements such as the speaker, the hearer and the entity or process talked about (topic), and accordingly discourse context refers to the knowledge about these major elements. How do these elements participating in discourse, such as the speaker, the hearer and topic, influence the metaphorical uses in a discourse? Let's begin with one example which shows that topics of discourses govern the conceptualization of the novel and unconventional metaphors. The background of the example is like this: in the January 25-27 issue of the American newspaper USA TODAY, there was a long article about cyclist Lance Armstrong's confessions about his doping as well as his not so satisfying performance in cycling. So, concerning the topic discussed in this article, one specialist in crisis management gave the following comment in an interview:

(6) "To use an analogy from Tour de France, he is still in the mountain stage, and will be for some time" (Cited from Kovecses, 2015,p.54)

It should be pointed out that in example (6) the specialist have enough knowledge about the topic of the discourse, such as Armstrong's doping scandal, his career experience of participating in Tour de France events several times as well as the encyclopedic knowledge that this race has several mountain stages, all of which help trigger the conceptual metaphor "ACTION IS MOTION" and the corresponding metaphorical utterance meaning that Armstrong is still on his way towards success.

Knowledge about the speaker also has a similar influence on the metaphorical meaning making in discourse. For example, as a painter who painted mural advertisements in New York City, Frank Jump has AIDS, and his knowledge about himself helps shape his use of the novel metaphor SURVIVING AIDS DESPITE PREDICTIONS TO THE CONTRARY IS FOR THE OLD MURAL ADVERTISEMENTS TO SURVIVE THEIR EXPECTED "LIFE SPAN" (Kovecses, 2005).

Besides, surrounding discourse, also called linguistic context, plays a role in the choice of different metaphors, as is shown in the following example:

(7)When the Electoral Commission came to make its choice between referring the case to the police and taking no action it was this defense, described by an authoritative source as showing "contempt" for the law, which helped to tilt 
the balance-and Mr. Hain-over the edge. (Cited from Kovecses, 2015,p.110)

Here in this example, "tilt the balance" is a conventional metaphorical expression which is derived from the conceptual metaphor UNCERTAINTY IS BALANCE, whereas the expression "[tilt] Mr. Hain over the edge" is a novel metaphorical expression produced under the influence of the preceding discourse.

Moreover, discourse context also shows its great influence upon the metaphorical meanings of Chinese network catchphrases, which can be supported from the following discussion:

(8) 暖气 太 给力了。

nuanqi tai geili le.

heating very giving force

"The heating is very efficient."

(9) 这个 表演太 给力 了。

zhege biaoyan tai geili le

this performance very giving force.

"This performance is very good."

(10) 关于 艳照门, 我是 打酱油的。 guan yu yanzhaomen, wo shi da jiangyou de. as for news of illicit love, I just buy soysauce "As for news of illicit love, I show indifference to it."
(11)为什么 公司越大打酱油的越多?
wei shenm gongsi yueda dajiangyou de yueduo?
why company bigger people who buy soysauce more

"Why the bigger the company is, the more indifferent people are there in it?"

In example (8) and (9), the new expression “给力” means being brilliant or awesome, from which we get the “'力'IS A SUBSTANCE” metaphor. Once “给力” appears in different discourses, new metaphorical meanings will be created. For example, in the above examples there are different conceptual metaphors entailed respectively: “力”IS THE efficiency OF HEATING,“力” IS A GOOD PERFORENCE. From the newly-created conceptual metaphors above, it is easily seen that previous discourses can influence the meaning making of these underlying conceptual metaphors, making the target domain“力”more specific and much easier to understand.

As for the new expression“打酱油”in examples(10)and(11), literally it means the act of buying soy sauce, and in these examples it is used to express an attitude of indifference figuratively. It is supposed that there exists a conceptual metaphor "INDIFFERENCE IS THE ACT OF BUYING SOY SAUCE" in these Chinese network catchphrases. Similar to the expression“给力”, the expression“打酱油”is also endowed with specific figurative meanings once it appears in different discourse contexts. And we attribute these figurative meanings to the conceptual metaphors newly created in different discourse contexts, such as "THE ATTITUDE TO NEWS EVENTS IS THE ACT OF BUYING SOY" and "NO CARING ABOUT COMPANY IS THE ACT OF BUYING SOY". From what has been discussed above, it can be seen that discourse context also shapes the metaphorical meaning making of Chinese network catchphrases.

\section{Analysis from the Bodily Context}

Bodily context, as its name suggests, takes body as one kind of contexts, and it includes many factors relating to the body ,say, from organism of human body ,mental state of health to the universal or specific bodily experience. Kovecses(2015) states that the body, in particular, those aspects of it that can be activated in the ongoing situation, can influence metaphorical meaning making. Take the bodily experience for example: when we are happy, we have the bodily experience of being physically up and active rather than down and inactive, and these experiences help shape the corresponding emotional metaphors, such as expressions" I am in high spirits", "I feel low" etc. Moreover, specific bodily experience also can influence particular people's use of metaphors. An experiment of Casasanto (2009) shows that left-handers are more likely to use metaphorical expressions governed by conceptual metaphor "moral is left" when they want to express something relating to morale. How does bodily context influence the meaning making of Chinese network catchphrases? An explanation of this question can be obtained from discussing the following examples:

(12) 雷人的镜头。

lei ren de jingtou.

to thunder people de scene.

"shocking scene."
(13) 好雷人啊, 芙蓉姐姐开唱了。 hao lei ren a, Furong jiejie kai chang le.
Very to thunder people, Furong sister began sing.
"(it is)Very shocking that Furong sister began to sing."

(14) 通过 “海选”, 村民的 民主 权利 得到了 充分的

保障。

tongguo "hai xuan", cunmin de minzu quanli dedao le chongfen de 
baozhang.

through sea election, villagers democracy rights gain enough

protection.

"Through mass-election, democracy rights of villagers gained enough protection."

(15)“海选” 选出了县长。

"hai xuan" xuanchu le xianzhang.

sea election select mayor.

"Through mass-election, the mayor was selected."

"Lei ren"(雷人) in examples(12)and(13) has the metaphorical meaning of being surprised, shocked and speechless, which has something to do with its original meaning — one kind of natural phenomenon of discharging. We usually have the bodily experience of being scared and shocked when hearing thunder, and the metaphorical meaning of Chinese character"lei"( to thunder )derives from such a universal experience, which in turn brings about the production of the underlying conceptual metaphor "SHOCK OR SURPRISE IS THUNDER" as well as its corresponding metaphorical expressions.

"hai xuan(海选)" in examples (14) and (15) refer to a way of election occurring in the mass people. Similarly, the meaning making of the metaphorical expression“hai xuan(海选)"is also influenced by the bodily context: We usually have the visual experience of broadness and vastness every time when we watch ocean and this visual experience helps shape the conceptualization of the underlying metaphor "THE LARGE NUMBER OF CANDIDATES IS OCEAN" and its corresponding linguistics metaphors. Discussions of the above examples (12) - (15) clearly explain how bodily context influences the metaphorical meaning making of Chinese network catchphrases.

\section{Analysis from the Conceptual-cognitive Context}

Conceptual-cognitive context includes the conceptual system consisting of construal operations and a system of concepts, history memory (short-term memory or long-term memory), interests and concerns about the world, and other factors. This kind of context can influence the meaning construction of metaphorical expressions relating to the same topic. Or in other words, given an intended metaphorical meaning, the metaphorical conceptual system can be exploited to produce best choices of metaphors. For example, the conceptual metaphor "argument is war" can be made use of to produce such a metaphorical expression as "He defends his opinions on this matter". Also, some of the concepts that are in a metaphorical relationship with one another may lead to the production and comprehension of novel metaphors, such as "My wife is an anchor". Here, for sake of space ,this article won't give any examples that demonstrate how history, memory, interests and concerns about the world as well as other factors influence metaphorical meaning making. Now let's look at how conceptual-cognitive context plays an important function in the comprehension and production of Chinese network catchphrases.

(16) 在 “河蟹” 社会乱停车现象非常严重。 zai "hexie" shehui luan tingche xianxiang feichang yanzhong. In crab society parking carelessly very serious.

"In the unharmonious society parking carelessly is very serious."

(17)“河蟹”社会 的公务员真是 “敬业”, 时刻显示着自己的优越感。 "hexie" shehui de gongwuyuan zhenshi "jingye", shi ke xianshizhe ziji de youyuegan. crab society de public servant really "delicated", every minute showoff own priorities. minute."

"In the unharmonious society, public servants are really 'delicated', showing off their own priorities every

Here, in these examples, “ “crab” society (“河蟹”社会)”is the homophonic replacement of"“ "harmonious’ society( ‘和 谐'社会) ” in Chinese, which imparts a flavor of humor and irony of unharmony and inequality in the society. The meaning construction of “hexie'shehui (“河蟹”社会)” involves the conceptual-cognitive context for the following reasons: First, the long-term memory fostered in the Chinese culture tells us that crabs are the representation of ignorance, which brings about the conceptual metaphor "ARROGANCE IS A CRAB"; second, in our conceptual system, there exist conceptual metaphors, such as "PEOPLE ARE ANIMALS" and "SOCIETY IS A RIVER". Given the above three conceptual metaphors in human's conceptual-cognitive system , it is no wonder that Chinese people conceptualize this unfair phenomenon by means of the metaphorical expression“ “crab” society（“河蟹”社会）”.

\section{CONCLUDing REMARKS}

In the article a cognitive explanation of Chinese network catchphrases from a new perspective, that is, contextual perspective,is given. This new explanation is not in total accordance with the main tenets of conceptual metaphor theory in that it pays more attention to the role of context in the meaning making of Chinese network catchphrases. The main theory this paper makes advantage of is Kovecses' context theory concerning metaphor studies, under the guidance of which the conclusion is derived that the meaning of Chinese network catchphrases is not solely from conceptual metaphors, their mappings as well as their potential entailments, but also depends heavily on contextual factors, such as situational context, discourse context, bodily context and conceptual-cognitive context. In general, in light of such an 
analysis, it can be easily seen that context is of great significance in metaphor studies and that there exists a wide range of contextual factors governing the creation and comprehension of Chinese network catchphrases in the actual network communication, which seem to be more in line with the new discovery about the nature of human cognition, that is, grounding cognition. (see Pecher and Zwaan, 2005;Gibbs, 2006a; Barsalou, 2008).

\section{REFERENCES}

[1] Barsalou, Lawrence W. (2008). Grounded cognition. Annual Review of Psychology, 59, 617-645.

[2] Boers, F. \& M. Demecheleer. (1997). A few metaphorical models in (western) economic discourse. In W.A.Liebert, G. Redeker,and L.Waugh (eds.). Discourse and Perspective in Cognitive Linguistics (pp.115-129). Amsterdam: John Benjamins.

[3] Boers,F.\& M. Demecheleer. (2001).Measuring the impact of cross-cultural differences on learners' comprehension of imageable idioms. ELT Journal, 55, 255-262.

[4] Casasanto, D. (2009). Embodiment of abstract concepts: good and bad in right and left handers. Journal of Experimental Psychology: General, 3,351-367.

[5] Firth, J.R. (1951). Papers in Linguistics, 1934-1951. London: Oxford University Press.

[6] Gibbs,Raymond W. Jr. (2006a). Embodiment and Cognitive Science. Cambridge: Cambridge University Press.

[7] Gibbs,Raymond W.Jr. (2006b). Metaphor interpretation as embodied simulation. Mind and Language, 21, 434-458.

[8] Halliday, M. A. K. (1975). Learning How to Mean: Explorations in the Development of Language. (Explorations in Language Study Series). London: Arnold.

[9] He.Z.R \&Ran.Y.P. (2006). A general introduction to pragmatics. Hunan: Hunan Educational Press.

[10] He.Z.R. (2014). Memetic understanding of language in fashion. Shandong Foreign Language Teaching, 2, 8-13.

[11] Kolodny, Annette. (1975). The Lay of the Land: Metaphor as Experience and History in American Life and Letters. Chapel Hill: The University of North Carolina Press.

[12] Kolodny,Annette. (1984). The Land Before Her: Fantasy and Experience of the American Frontiers (pp.1630-1860).Chapel Hill: The University of North Carolina Press.

[13] Kovecses,Z. (2005). Metaphor in Culture: Universality and Variation. Cambridge: Cambridge University Press.

[14] Kovecses,Z. (2010). A new look at metaphorical creativity in cognitive linguistics. Cognitive Linguistics, 21(4), $663-697$.

[15] Kovecses, Z. (2015). Where Metaphors Come From: Reconsidering Context in Metaphor. New York: Oxford University Press.

[16] Lakoff, G \& M. Johnson. (1980). Metaphors We Live By. Chicago: The University of Chicago Press.

[17] Leech, G.N. (1983). Principle of Politeness. London: Longman.

[18] Lin.Y. (2012). A pragmatic analysis of present popular internet popular language. Journal of Yichang College, 2, 56-59.

[19] Lyons, J. (1977). Semantics. Cambridge: Cambridge University Press.

[20] Malinowski, B. (1930). The problem of meaning in primitive languages In Ogden, C.K \& I.A. Richards (eds.). The Meaning of Meaning (pp. 296-336). Routledge \& Kegan Paul.

[21] Pecher, Diane and Rolph A. Zwaan (eds.). (2005). Grounding Cognition: The Role of Perception and Action in Memory, Language, and Thinking. Cambridge: Cambridge University Press.

[22] Semino, E. (2008). Metaphor in Discourse. Cambridge: Cambridge University press.

[23] Van Dijk, T.A. (2008). Discourse and Context. New York: Cambridge University Press.

[24] Van Dijk, T.A. (2009). Society and Discourse: How Social Contexts Influence Text and Talk. Cambridge: Cambridge University Press.

[25] Wang.J.H. (2002). The constitution and classification of context .Applied linguistics, 3,2-9

Hongyan Hua was born in zhengzhou, China in 1983. She is now a PHD Candidate in Southwest University, China. Her research interests include pragmatics and cognitive linguistics.

She is a member of China Pragmatics Association. 